Vol. 16, 419-431, 2020

wWw.aspbs.com/jbn

\title{
Physicochemical Characterization, Toxicity and In Vivo Biodistribution Studies of a Discoidal, Lipid-Based Drug Delivery Vehicle: Lipodisq Nanoparticles Containing Doxorubicin
}

\author{
Maria Lyngaas Torgersen ${ }^{1, *, \dagger}$, Peter J. Judge ${ }^{2, \dagger}$, Juan F. Bada Juarez ${ }^{2}$, Abhilash D. Pandya ${ }^{3}$, \\ Markus Fusser ${ }^{3}$, Charlie W. Davies², Matylda K. Maciejewska², Daniel J. Yin², \\ Gunhild M. Mælandsmo ${ }^{3,4}$, Tore Skotland ${ }^{1}$, Anthony Watts ${ }^{2, *}$, and Kirsten Sandvig ${ }^{1,5}$ \\ ${ }^{1}$ Department of Molecular Cell Biology, Institute for Cancer Research, Oslo University Hospital, N-0379, Oslo, Norway \\ ${ }^{2}$ Department of Biochemistry, University of Oxford, Oxford, OX1 3QU, UK \\ ${ }^{3}$ Department of Tumor Biology, Institute for Cancer Research, Oslo University Hospital, N-0379, Oslo, Norway \\ ${ }^{4}$ Institute of Medical Biology, Faculty of Health Sciences, The Arctic University of Norway-University of Tromsø, N-9037, Tromsø, Norway \\ ${ }^{5}$ Department of Biosciences, University of Oslo, N-0316, Oslo, Norway
}

\begin{abstract}
Many promising pharmaceutically active compounds have low solubility in aqueous environments and their encapsulation into efficient drug delivery vehicles is crucial to increase their bioavailability. Lipodisq nanoparticles are approximately $10 \mathrm{~nm}$ in diameter and consist of a circular phospholipid bilayer, stabilized by an annulus of SMA (a hydrolysed copolymer of styrene and maleic anhydride). SMA is used extensively in structural biology to extract and stabilize integral membrane proteins for biophysical studies. Here, we assess the potential of these nanoparticles as drug delivery vehicles, determining their cytotoxicity and the in vivo excretion pathways of their polymer and lipid components. Doxorubicin-loaded Lipodisqs were cytotoxic across a panel of cancer cell lines, whereas nanoparticles without the drug had no effect on cell proliferation. Intracellular doxorubicin release from Lipodisqs in HeLa cells occurred in the low-pH environment of the endolysosomal system, consistent with the breakdown of the discoidal structure as the carboxylate groups of the SMA polymer become protonated. Biodistribution studies in mice showed that, unlike other nanoparticles injected intravenously, most of the Lipodisq components were recovered in the colon, consistent with rapid uptake by hepatocytes and excretion into bile. These data suggest that Lipodisqs have the potential to act as delivery vehicles for drugs and contrast agents.
\end{abstract}

KEYWORDS: Lipodisq, Nanoparticles, Drug Delivery, Doxorubicin, SMA.

\section{INTRODUCTION}

Overcoming the low solubility of novel therapeutic compounds is a key challenge for the pharmaceutical industry [1]. Encapsulation of therapeutic agents within nanoparticles (NPs) may protect drug molecules from enzymatic degradation, maintain their efficacy and improve pharmacokinetics in vivo [2,3]. NPs used for drug delivery typically have a diameter larger than $50 \mathrm{~nm}$, and

\footnotetext{
*Authors to whom correspondence should be addressed.

Emails: marialy@rr-research.no, anthony.watts@bioch.ox.ac.uk

These two authors contributed equally to this work.

Received: 3 November 2019

Accepted: 28 June 2020
}

it is not known whether smaller NPs would give a better uptake in tumors due to the Enhanced Permeability and Retention (EPR) effect [4].

Lipid-based drug delivery systems, such as liposomes, micelles or nanodiscs $[5,6]$ are of interest since lipids can easily be metabolized in the body. They provide a unique amphipathic environment, with the ability to carry insoluble (or sparingly soluble) molecules in aqueous solutions. Doxil $^{\circledR} /$ Caelyx ${ }^{\circledR}$, a liposomal formulation containing doxorubicin (DOX) for cancer therapy, was FDA-approved in 1995, and was the first liposome-based product to enter the market $[7,8]$. Several liposome-based products are now available [9]. Here we evaluate the ability of 
Lipodisq NPs (10 nm in diameter, $4.5 \mathrm{~nm}$ thickness) composed of a hydrolysed co-polymer of styrene and maleic anhydride (SMA) [10] and 1,2-dimyristoyl-sn-glycero-3phosphocholine (DMPC; PC 14:0/14:0) [11, 12], to act as drug delivery vehicles for DOX. Since the Lipodisq nanoparticles are much smaller $(10-20 \mathrm{~nm})$ than the FDA approved liposomes $(>50 \mathrm{~nm})$, it is possible that Lipodisq NPs will give a higher uptake of drugs in tumors and better penetration into the tumor tissue. Additionally, liposomal larger NPs have limited stability in the body, unknown long-term toxicity, and poor EPR effect $[13,14]$.

DOX is active against a broad spectrum of tumors including breast, lung, gastric, ovarian, pancreatic, prostate, multiple myeloma and some types of leukaemia $[15,16]$. The drug exerts its cytotoxicity by interchelating with DNA base pairs, as well as by interacting with several molecular targets such as DNA topoisomerase II [16]. DOX has low solubility in water, rendering its administration to patients difficult. Several side effects are observed in patients treated with DOX, such as nausea, skin irritation and fever, the most dramatic being heart failure (cardiomyopathy) $[15,17]$. SMA polymer has been used extensively in structural biology to extract proteins directly from native membranes without the need for conventional detergents [10, 11]. The resulting Lipodisq NPs (also known as SMALPs), consisting of a coin-shaped lipid bilayer stabilized by a polymer annulus [11] are used extensively for characterization of integral membrane proteins by different techniques, including cryo electron microscopy and X-ray crystallography [10]. Hydrophobic interactions drive the spontaneous self-assembly of Lipodisq NPs in aqueous conditions, creating a monodisperse suspension at physiological $\mathrm{pH}$, temperature and ionic strength $[10,18]$.

Here we evaluate the ability of Lipodisq NPs composed of a hydrolysed co-polymer of styrene and maleic anhydride (SMA) [10] and 1,2-dimyristoyl-sn-glycero-3phosphocholine (DMPC; PC 14:0/14:0) [11, 12], to act as drug delivery vehicles for DOX. The uptake of the NPs by cancer cells is studied, as well as the release of DOX in the acidic environments of lysosomes and the resulting cytotoxic effects across a panel of cancer cell lines. The in vivo fates of the NP components and the drug were investigated after intravenous injection into mice and we observed uptake of the Lipodisq NPs by the liver, followed by rapid excretion in the bile. Our data suggest that intravenously injected Lipodisq NPs have a potential as delivery vehicles for drugs or as carriers for contrast agents, especially to the liver and lower gastrointestinal tract.

\section{MATERIALS AND METHODS Materials}

Lipids including 1,2-dimyristoyl-sn-glycero-3phosphocholine (DMPC), 1,2-dimyristoyl-sn-glycero-3phospho-(1'-rac-glycerol) (DMPG) and 1,2-dilauroyl-sn -glycero-3-phosphoethanolamine (DLPE), were purchased from Avanti Polar Lipids (Alabaster, AL). SMAnh (a non-hydrolyzed co-polymer of styrene: maleic anhydride in a 3:1 molar ratio) was kindly provided by Malvern Cosmeceutics Ltd (Worcester, UK). Doxorubicin (DOX) was from Cambridge Bioscience Ltd (Cambridge, UK) and Sulfo-Cyanine5 NHS ester (Cy5) were from Lumiprobe (Hannover, Germany). N,N-dimethylmethanamide (DMF), Dimethyl sulfoxide (DMSO), Tris(2-carboxyethyl)phosphine (TCEP) and Concanamycin A (ConA) were obtained from Sigma-Aldrich (St. Louis, MO). Bafilomycin A1 (BafA1) was from Enzo Life Sciences, Farmingdale, NY.

\section{Preparation of Lipodisq Batches \\ Preparation of Lipodisq NPS Containing DOX}

To prepare Lipodisq NPs containing different amounts of DOX, lipid (as a dry powder) and DOX (fresh stock solution in $\mathrm{ddH}_{2} \mathrm{O}$, added to yield 1,5 , or $10 \%$ molar ratio) were dissolved in a chloroform:methanol (2:1 v/v) mixture, which was evaporated under a $\mathrm{N}_{2}$ stream, and the resulting lipid film was allowed to dry under vacuum $\left(<10^{-5}\right.$ Torr) overnight. Depending on the application, the film was rehydrated with either $50 \mathrm{mM}$ phosphate buffer at $\mathrm{pH} 7.0$ or $50 \mathrm{mM}$ phosphate-buffered saline (PBS) at $\mathrm{pH} 7.4$ (containing $137 \mathrm{mM} \mathrm{NaCl}$ and $2.7 \mathrm{mM} \mathrm{KCl}$ ). The lipid suspension was then sonicated using a bath sonicator (5 min at room temperature, RT). Afterwards, 5-10 freeze thaw cycles were applied (in liquid nitrogen and then a water bath at $\left.42{ }^{\circ} \mathrm{C}\right)$. Extrusion was performed using a Mini-Extruder (Avanti Polar Lipids, Alabaster, AL) and two $1000 \mu \mathrm{l}$ syringes. The solution was extruded first using a Whatman $0.4 \mu \mathrm{m}$ filter and then a Whatman $0.1 \mu \mathrm{m}$ filter (10 mm diameter) (Sigma) at a temperature at least $5{ }^{\circ} \mathrm{C}$ higher than the phase transition temperature of the lipid when hydrated (approximately $30^{\circ} \mathrm{C}$ for DMPC). Between 10 and 20 passages of the mixture through each type of filter were necessary to obtain a clear red suspension. Finally, SMA polymer was added in a 1:1.25 w/w lipid-to-SMA ratio. The mixture was then vortexed for a few seconds and maintained at $42{ }^{\circ} \mathrm{C}$ for $1 \mathrm{~h}$, before the sample was centrifuged $(14,000 \mathrm{~g}$, 5 min, RT).

The supernatant (of Lipodisq NPs containing DMPC and DOX) was concentrated prior to size exclusion chromatography using a Vivaspin column (MWCO 100 kDa, Millipore (Burlington, MA)) and then applied to a $5 \mathrm{ml}$ HiTrap column (GE Healthcare, Chicago, IL) that had been equilibrated with phosphate or PBS buffer (depending on the application). Coloured fractions were collected, concentrated and stored at $4{ }^{\circ} \mathrm{C}$ for further experiments. An overview of all Lipodisq NP preparations is shown in Table I. 
Table I. The composition of Lipodisq batches produced for the different applications.

\begin{tabular}{|c|c|c|c|c|}
\hline Application & Lipodisq name & Lipid & DOX (molar \%) & Dye \\
\hline \multirow{2}{*}{$\begin{array}{l}\text { Physiochemical } \\
\text { characterization }\end{array}$} & DMPC Lipodisqs & DMPC & - & - \\
\hline & DMPG Lipodisqs & DMPG & - & - \\
\hline \multirow{4}{*}{$\begin{array}{l}\text { Cellular uptake } \\
\text { and cytotoxicity }\end{array}$} & LQ-E & DMPC 2.2 mg/ml (3.2 mM) Cy5-DLPE 1\% & - & Cy5 conjugated to DLPE \\
\hline & LQ-1\% & DMPC 2.2 mg/ml Cy5-DLPE 1\% & $1 \% \mathrm{DOX}$ & Cy5 conjugated to DLPE \\
\hline & LQ-5\% & DMPC 2.2 mg/ml Cy5-DLPE 1\% & $5 \%$ DOX & Cy5 conjugated to DLPE \\
\hline & LQ-10\% & DMPC 2.2 mg/ml Cy5-DLPE 1\% & 10\% DOX (360 $\mu \mathrm{M})$ & Cy5 conjugated to DLPE \\
\hline \multirow{2}{*}{$\begin{array}{l}\text { Biodistribution } \\
\text { in mice }\end{array}$} & Lipodisq DLPE-Cy5 & DMPC 10 mg/ml, Cy5-DLPE $1 \%$ & - & Cy5 conjugated to DLPE \\
\hline & Lipodisq SMA-Cy5 & DMPC $10 \mathrm{mg} / \mathrm{ml}$ & - & Cy5 conjugated to SMA \\
\hline
\end{tabular}

Preparation of a Thiol Derivative of SMA

\section{Polymer (SMA-SH)}

Non-hydrolysed styrene and maleic anhydride (SMAnh) polymer was conjugated to cysteamine using a method adapted from Lindhoud et al. [19]. Cysteamine (15 mg) was added to $1 \mathrm{~g}$ SMAnh and mixed in DMF. A volume of $700 \mu \mathrm{l}$ of trimethylamine was added and the mixture stirred (30 min, RT). The resulting thiol derivative, SMAnh-SH, was precipitated by addition of approximately $30 \mathrm{ml}$ of $1 \mathrm{M}$ acetic acid and the precipitate was recovered after centrifugation (4000 g, 5-10 min, RT). DMF was removed by washing with water (between 5 and 10 times) and the sample was then lyophilized. The polymer was hydrolysed to obtain SMA-SH (from SMAnh$\mathrm{SH}$ ) by dissolving SMAnh-SH powder in $0.1 \mathrm{M}$ borate buffer, $100 \mathrm{mM}$ dithiothreitol (DTT) $\mathrm{pH} 8.5\left(100{ }^{\circ} \mathrm{C}\right.$, $4 \mathrm{~h}$ ). After cooling, the solution was dialysed overnight (MWCO $3.5 \mathrm{kDa}, 30 \mathrm{ml}$ cassette from ThermoFisher, (Waltham, MA)) against $1 \mathrm{mM}$ DTT, pH 8.0. The SMASH polymer was finally lyophilized and re-suspended in either PBS for further dye conjugation or in $1 \mathrm{mM}$ DTT, $\mathrm{pH} 8.0$ for long-term storage at a SMA-SH concentration of $125 \mathrm{mg} / \mathrm{ml}$.

\section{Preparation of Fluorophore-Labelled SMA (SMA-Cy5)}

Sulfo-Cyanine5 NHS ester (Cy5) (Hannover, Germany) was dissolved in $20 \mu \mathrm{l}$ DMSO and added directly to the SMA-SH previously dissolved in $50 \mathrm{mM}$ phosphate buffer, pH 7.4 supplemented with $5 \mathrm{mM}$ TCEP. The mixture was left to stir for $2 \mathrm{~h}$ in the dark at RT. Afterwards the polymer was extensively dialysed against a $50 \mathrm{mM}$ phosphate buffer containing $1 \mathrm{mM}$ DTT at $\mathrm{pH}$ 8.0. Unreacted dye and SMA-SH were removed by thin layer chromatography (TLC) using silica gel plates (Merck, Darmstadt, Germany) and a mobile phase of chloroform/methanol/water (5:5:1 v/v/v). SMA-Cy5 migrates with retention factors (Rf) between $0.4-0.7$ and the free dye with an $R=0.9$. SMA-Cy5 was extracted from the silica by solubilisation in methanol, followed by centrifugation (4000 g, 5 min, RT) and the supernatant was recovered and dried using a rotary evaporator. Once dried, the dyelabelled polymers were solubilized in PBS supplemented with $1 \mathrm{mM}$ DTT, pH 8.0.

\section{Preparation of Fluorophore-Labelled DLPE} Lipid (DLPE-Cy5)

Lipodisq NPs were also labelled with Cy5 by coupling to 1,2-dilauroyl-sn-glycero-3-phosphoethanolamine (DLPE; PE12:0/12:0). DLPE (4 mg, $6.90 \mu \mathrm{mol}$ ) and Sulfo-Cyanine5 NHS Ester (an $N$-hydroxysuccinimide ester derivative of the Cy5 dye Lumiprobe, Hannover, Germany) was conjugated to the lipid according to the literature [21], and purified by preparative TLC using a mobile phase of chloroform/methanol/water (95:25:4 $\mathrm{v} / \mathrm{v} / \mathrm{v})$. The successful synthesis and purification of DLPECy5 was verified by mass spectrometry and NMR spectroscopy (data not shown). ${ }^{1} \mathrm{H}$ and ${ }^{13} \mathrm{C}$ NMR spectra were recorded using a Bruker $500 \mathrm{MHz}$ spectrometer running Topspin $^{\text {TM }}$ software, measured against a residual solvent peak as an internal standard. High-resolution mass spectra were recorded on a Bruker ESI MicroTof mass spectrometer (Chemistry Research Laboratory, University of Oxford, $\mathrm{UK})$. This procedure resulted in formation of DLPE-Cy5 (6.78 mg, yield 93\%), a bright blue viscous solid.

\section{Physicochemical Characterization of Lipodisqs}

The fluorescence spectrum of DOX is sensitive to the polarity of its microenvironment and this property was therefore used to investigate how DOX interacts with Lipodisq NPs. Furthermore, iodide $\left(I^{-}\right)$quenches the fluorescence of DOX in solution [22, 23]. For the fluorescence quenching experiments, two samples were required for each lipid preparation: one containing KI (100 mM) and the other containing $\mathrm{KCl}(100 \mathrm{mM})$ in phosphate buffer ( $\mathrm{pH}$ 7.0). The buffer was added at the beginning of the preparation of the Lipodisq suspensions (addition of stock solution of $1 \mathrm{M} \mathrm{KCl}$ or $\mathrm{KI}$ to the Lipodisq-DOX sample). The fluorescence measurements were performed using a LS50B Luminescence Spectrometer from Perkin Elmer (Seer Green, UK). Excitation was performed at 480 $\mathrm{nm}$ and the emission spectra were recorded from $500 \mathrm{~nm}$ to $650 \mathrm{~nm}$. These measurements were performed in $500 \mu \mathrm{l}$ cuvettes with samples diluted 10 times with phosphate buffer. The temperature was maintained at $20{ }^{\circ} \mathrm{C}$ using a water bath.

Lipodisq particle size in each of the preparations was measured by dynamic light scattering (DLS) using a Malvern Zetasizer Nano S instrument (633 nm; disposable 
cuvettes), and data were processed using Malvern Zetasizer software (Great Malvern, UK).

\section{Cell Lines and Treatments}

All cancer cell lines used in this study were obtained from ATCC and routinely tested for mycoplasma. The MDA-MB-231 (triple-negative breast cancer, Claudin low) and SW480 (colorectal adenocarcinoma) were cultured in RPMI; the MDA-MB-468 (triple negative breast cancer, basal), HeLa (cervical cancer), HCT116 (colorectal cancer), SKBR3 (breast cancer, HER2+), and MCF7 (breast cancer, luminal A) were cultured in DMEM. All media were fortified with $10 \%(\mathrm{v} / \mathrm{v})$ fetal calf serum (Sigma-Aldrich, St. Louis, MO) and 100 units/ml penicillin/streptomycin (PenStrep ${ }^{\circledR}$, Sigma-Aldrich, St. Louis, $\mathrm{MO}$ ). The cells were seeded one or two days prior to experiments. For inhibitor studies, cells were pre-treated with the inhibitors at the indicated concentration for $1 \mathrm{~h}$ before addition of Lipodisq NPs.

\section{Cell Proliferation Measured by $\left[{ }^{3} \mathrm{H}\right]$ Thymidine Incorporation}

Incorporation of $\left[{ }^{3} \mathrm{H}\right]$ thymidine into DNA was used to estimate cell proliferation. Cells seeded at an initial cell density of 40,000-60,000 per well in a 24 well plate were treated with either free DOX, empty Lipodisqs (LQ-E), or Lipodisqs containing 1\% DOX (LQ-1\%), 5\% DOX (LQ$5 \%$ ) or $10 \%$ DOX (LQ-10\%), where the percentage of DOX indicates the molar ratio to the lipid. The compositions of all Lipodisq batches used are listed in Table I. After $6-24 \mathrm{~h}$ at $37^{\circ} \mathrm{C}$ (as specified in each figure legend) the cell medium was aspirated and substituted with serumfree cell medium containing $\left[{ }^{3} \mathrm{H}\right]$ thymidine $(2 \mu \mathrm{Ci} / \mathrm{ml}$, Perkin Elmer, Waltham, MA). The incubation was continued for $30 \mathrm{~min}$ at $37{ }^{\circ} \mathrm{C}$. The medium was removed and $5 \%(\mathrm{w} / \mathrm{v})$ trichloroacetic acid (TCA) was added. After 5 min the cells were washed twice with TCA and solubilized with $200 \mu \mathrm{l}$ of $0.1 \mathrm{M} \mathrm{KOH}$, before mixing with $3 \mathrm{ml}$ scintillation fluid (Perkin Elmer, Waltham, MA). The radioactivity was counted for $1 \mathrm{~min}$ in a scintillation counter (Tri-Carb 2100TR, Packard Bioscience, Arvada, $\mathrm{CO})$. To assess the stability of the Lipodisqs and the release of DOX from the Lipodisqs, the Lipodisqs were pre-treated as described in each figure legend. Then half of the solution was filtered through a Centrifree ${ }^{\circledR}$ Ultrafiltration Device (Sigma-Aldrich, St. Louis, MO) that is commonly used for separating free from bound therapeutic drugs in biological samples. The filtration was performed in a Universal $320 \mathrm{R}$ centrifuge (Hettich, Tuttlingen, Germany) at $1800 \mathrm{~g}$ for $7 \mathrm{~min}$. Both the filtrate and the unfiltered half were diluted further $(1: 40)$ in complete medium and added to HeLa cells. Thymidine incorporation was assessed after time points indicated in each figure legend.

\section{MTT Cell Viability Assay}

Cytotoxicity was assessed by the MTT (4,5dimethylthiazol-2-yl)-2,5-diphenyltetrazolium bromide) cell viability test. Cells seeded at an initial density of 5000 or 8000 cells per well in a 96 well plate were treated with increasing concentrations of free DOX or with equivalent concentrations of DOX-loaded Lipodisqs (LQ-10\%) and the same dilutions of empty Lipodisqs (LQ-E). After $48 \mathrm{~h}$ at $37{ }^{\circ} \mathrm{C}$ the cell medium was aspirated, $100 \mu \mathrm{l}$ of medium containing a final concentration of $250 \mu \mathrm{g} \mathrm{MTT} / \mathrm{ml}$ was added, and the incubation was continued for $3 \mathrm{~h}$ at $37{ }^{\circ} \mathrm{C}$. The formazan-particles formed were subsequently dissolved in DMSO/0.25\% $\mathrm{NH}_{4} \mathrm{Cl}$ during vigorous shaking for $10 \mathrm{~min}$, and the absorbance was read in a plate reader (BioTek, Winooski, VT) at $570 \mathrm{~nm}$ (subtracting background absorbance at $650 \mathrm{~nm})$.

\section{Live-Cell Confocal Fluorescence Microscopy}

HeLa cells were seeded in 8-well Lab-Tek chamber slides (VWR, Radnor, PA) at a density of 30,000 cells per well one day prior to experiments. For visualisation of lysosomes, the cells were transduced with the lysosomal marker BacMam CellLight ${ }^{\mathrm{TM}}$ LysosomesRFP (Invitrogen, Carlsbad, CA) according to the manufacturer's recommendations. Empty Cy5-labeled Lipodisqs (LQ-E) were added in fresh complete medium $16 \mathrm{~h}$ later. Lysosomes were also detected with the acid-sensitive lysosomal dye Lysotracker Green (100 nM, Invitrogen, Carlsbad, CA). The dye was added 5 min before imaging. The cells were imaged using a Zeiss LSM780 laser scanning confocal microscope (Carl Zeiss Microscopy, Jena, Germany) equipped with an Ar-Laser multiline (458/488/514 nm), a DPSS56110 laser $(561 \mathrm{~nm})$, and a Zeiss Plan-Apochromat $63 \times$ /1.40 Oil DIC M27 objective. For visualisation of DOX, fluorescence in DOX-loaded Lipodisqs LQ-10\% was used.

\section{Biodistribution in Mice}

The animal experiments were approved and performed according to the Norwegian Animal Research Authority (Permit number 7837) and were conducted according to the regulations of the Federation of European Laboratory Animal Science Associations (FELASA). The mice were kept under pathogen-free conditions, at constant temperature $\left(21.5 \pm 0.5{ }^{\circ} \mathrm{C}\right)$ and humidity $(55 \pm 5 \%) ; 15$ air changes/h and a $12 \mathrm{~h}$ light/dark cycle. They had access to distilled water ad libitum. All mice used were female athymic nude foxn $1^{\nu}$ mice (age 5-6 weeks and body weights of 18-20 g), locally bred at the Department of Comparative Medicine, Oslo University Hospital, Norway.

Lipodisqs labelled with Cy5 either bound to the polymer SMA or to the lipid DLPE (Table I) were used to study the biodistribution in healthy mice using an IVIS $^{\mathrm{TM}}$ Spectrum 
in vivo imaging system (Perkin Elmer). Mice were intravenously injected with these two formulations of Lipodisqs (injected volume of $100 \mu \mathrm{l}$ with a dose of $100 \mathrm{mg} / \mathrm{kg}$ lipid) and saline as a control. The mice were given $4 \%$ sevoflurane gas anaesthesia using multiple masks. The excitation/emission wavelength pair of $640 / 680 \mathrm{~nm}$ was found to give the best signal-to-noise ratio and this setting was thus used for imaging of the NPs. As described below, two studies were performed and whole body images were obtained either immediately after injection of substance or 4 and $24 \mathrm{~h}$ after injection; the animals were then sacrificed by cervical dislocation and organs were harvested at the time points described. The organs were imaged ex vivo with the IVIS scanner using the same settings as above. Relative signal intensity in the organs was calculated, using Living Image software (Perkin Elmer), as radiant efficiency (Emission light [photons/sec/ $\mathrm{cm}^{2} / \mathrm{str}$ ] Excitation light $\left.\left[\mu \mathrm{W} / \mathrm{cm}^{2}\right] \times 10^{9}\right)$ per pixel of the region of interest, which was drawn around the respective organ.

\section{RESULTS AND DISCUSSION}

DOX is Stably Incorporated into $10 \mathrm{~nm}$ Lipodisqs Lipodisq NPs containing DOX were formed by the addition of SMA polymer to liposome suspensions containing the drug. The self-assembly of the discoidal particles is spontaneous and is driven by hydrophobic interactions, as the styrene groups of the polymer interact directly with the non-polar lipid tails [10]. NP formation was verified by dynamic light scattering and all Lipodisq preparations containing DOX were found to have a similar size with a diameter of $10 \pm 2 \mathrm{~nm}$ (data not shown) [11].

DOX has previously been shown to partition into model membranes containing DMPC, by allowing its planar aromatic rings to insert between the lipid acyl chains and its polar headgroup (containing a primary amine) to interact with the negatively charged lipid phosphate groups [24]. We proposed that DOX would be incorporated into the Lipodisq NPs in a similar manner and that the delocalised electron system, that gives rise to the fluorescence properties of the drug, would be inaccessible to the aqueous phase. The pKa of the primary amine group in DOX is 8.2 (PubChem database). In our experiments, conducted at $\mathrm{pH} \mathrm{7.0,} \mathrm{the} \mathrm{amino} \mathrm{carbohydrate} \mathrm{moiety} \mathrm{of}$ DOX would be expected to be mostly positively charged in solution, thus preventing deep penetration into the lipid layer. In addition, the lateral pressure profile, also replicated by the Lipodisq NPs, has been reported to hinder the deep penetration of DOX into lipid bilayers [25]. The DOX fluorescence emission spectrum is highly sensitive to its microenvironment and the drug dimerizes at high concentrations in solution $\left(K_{d} \sim 0.2 \mathrm{mM}\right)$, resulting in self-quenching $[26,27]$. Fluorescence quenching of the DOX may also be achieved with the addition of $I^{-}$ ions, which can interact with the aromatic ring system (Fig. 1(A)) [22, 23]. We therefore compared the relative fluorescence intensities of free DOX (in solution) and DOX in Lipodisqs (Table I) in the presence of $100 \mathrm{mM}$ $\mathrm{Cl}^{-}$and $100 \mathrm{mM} \mathrm{I^{- }}$ (Fig. 1(B)). An increased fluorescence intensity of DOX in the Lipodisq NPs relative to the solution sample was observed; this was likely caused by a reduction in the dimerization of DOX upon incorporation into the NPs [26, 27]. DOX in Lipodisq NPs was quenched much less by iodide than DOX in free solution (Fig. 1(C)), suggesting that in the NPs, the drug is not solvent accessible and is protected by the lipid environment of the Lipodisq. Lipodisqs comprised of DMPG instead of DMPC, showed very similar (but slightly reduced) quenching behaviour to DMPC Lipodisqs (Figs. 1(B, C)), indicating that lipid charge does not markedly affect stability, or formation of Lipodisqs-DMPG is anionic at $\mathrm{pH}>4.0$.
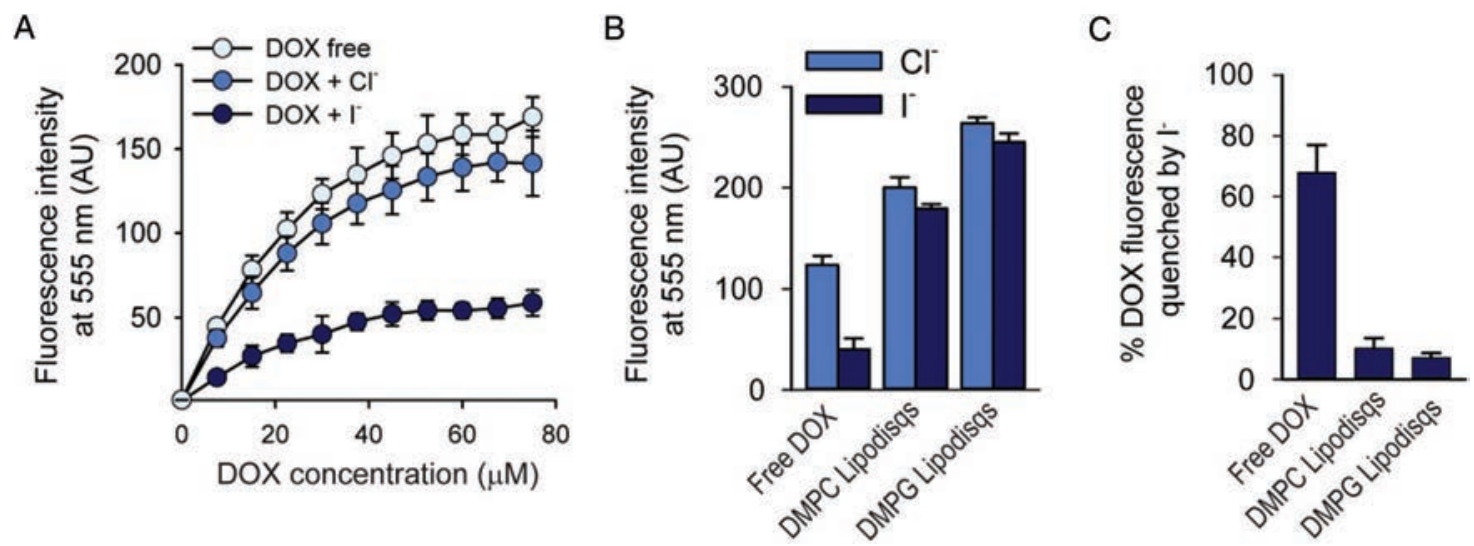

Figure 1. DOX is less susceptible to fluorescence quenching when incorporated in Lipodisqs than in solution. (A) Fluorescence measured with increasing concentrations of DOX and the effect of adding $100 \mathrm{mM} \mathrm{KI}$ or $\mathrm{KCl}$. (B-C) Comparison of relative fluorescence intensities and quenching of DOX in solution versus in Lipodisqs. Peak fluorescence measurements of DOX formulations (30 $\mu \mathrm{M}$ DOX, corresponding to a 1\% drug: lipid molar ratio in Lipodisqs containing 2 mg of DMPC or DMPG) in $100 \mathrm{mM} \mathrm{KCl}$ versus $100 \mathrm{mM} \mathrm{KI}(B)$. Percentage of $\mathrm{DOX}$ fluorescence quenched by ${I^{-}}^{-}$against the $\mathrm{Cl}^{-} \mathrm{control}^{(C)}$; $n=5$; error bars: one standard deviation. 


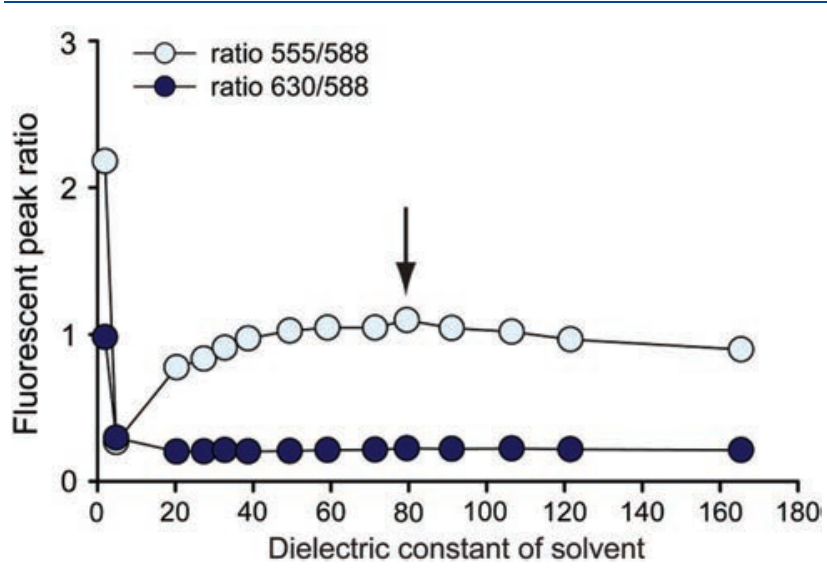

Figure 2. Fluorescence peak ratios of DOX in solvents of different dielectric constant. DOX was dissolved to a concentration of $30 \mu \mathrm{M}$ in each solvent, except the two with the lowest dielectric constants (hexane and chloroform) which were saturated with the maximum concentration of DOX, but which was lower than $30 \mu \mathrm{M}$. The black arrow overlaid on the graph indicates water as the solvent.

The sensitivity of the fluorescence peak ratios of DOX to the polarity of its environment [28] was used to probe the average local dielectric constant in the microenvironment of the drug. DOX was dissolved in different solvents, and the dielectric constants were taken from Wohlfarth [29]. The ratios of the intensities of the emission peaks, i.e., $555 \mathrm{~nm} / 558 \mathrm{~nm}$ and $630 \mathrm{~nm} / 588 \mathrm{~nm}$, were plotted (Fig. 2). The $555 \mathrm{~nm} / 558 \mathrm{~nm}$ ratio was 1.09 and the $630 \mathrm{~nm} / 588 \mathrm{~nm}$ ratio was 0.21 , indicating that the average local dielectric constant of DOX is between 50 and 110 , consistent with the position of the drug close to the charged lipid headgroups and glycerol moiety [25]. Together these fluorescence data suggest that the location of DOX is likely to be around the glycerol moieties of the phospholipids, with the positive charge from the amino group of DOX protruding from the Lipodisq NPs (Fig. 3).

\section{DOX is Rapidly Released from Lipodisqs Upon Cellular Uptake}

To assess the cytotoxicity of DOX-loaded Lipodisq NPs, their effect on cell proliferation was determined by measuring thymidine incorporation. HeLa cells were treated for $24 \mathrm{~h}$ with increasing concentrations of either empty Lipodisqs (LQ-E), or Lipodisqs containing 1\% DOX (LQ$1 \%$ ), $5 \%$ DOX (LQ-5\%) or $10 \%$ DOX (LQ-10\%). The DOX-containing NPs clearly reduced cell proliferation (Fig. 4(A)). When the data were plotted as a function of NP DOX concentration, the curves fully overlapped (Fig. 4(B)), suggesting that Lipodisq NP cytotoxicity strictly correlates with DOX content.

Thymidine incorporation into HeLa cells was used to determine how and when DOX is released from Lipodisq NPs. First, we assessed whether DOX is released from

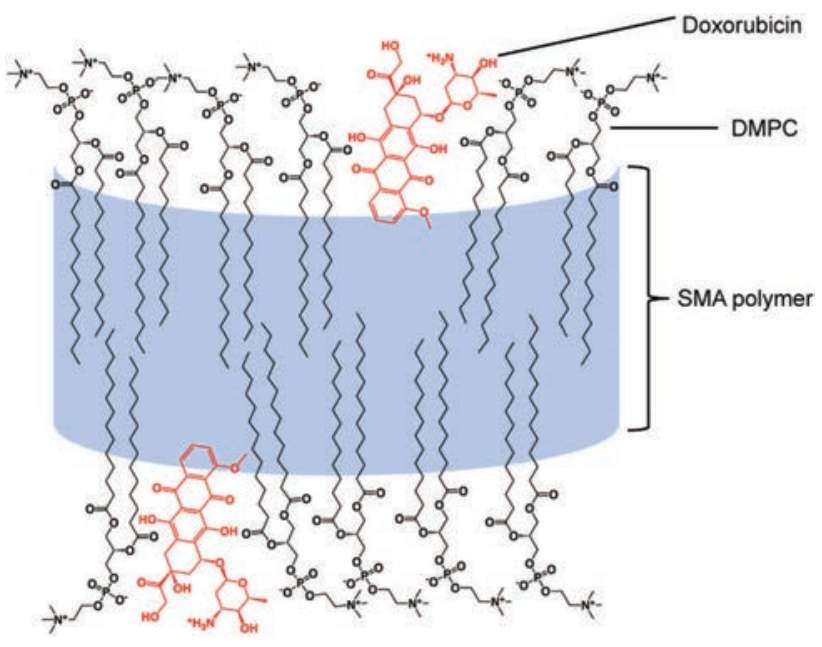

Figure 3. Illustration of the proposed location of DOX within a DMPC Lipodisq. The DOX molecules were adapted from Dupou-Cezanne et al. [25], whilst the DMPC molecules were from the Avanti website.

the NPs in the absence of cells, for example by nonspecific interactions with serum proteins in complete growth medium (see schematic drawing of workflow in Figure 5(A)). LQ-5\% was incubated in complete medium for increasing periods of time (3-29 h) at $37{ }^{\circ} \mathrm{C}$ before filtration through a Centrifree spin column, to separate the free from the bound drug. Free DOX molecules pass through the column, whereas drug incorporated in NPs is retained by the Ultracel ${ }^{\circledR}$ regenerated cellulose membrane. No reduction in cell proliferation was observed when cells were treated with the filtrate, suggesting that Lipodisq NPs are stable in complete medium (Fig. 5(B)). In contrast, unfiltered NPs displayed potent cytotoxicity, as expected (Fig. 5(B)). Free DOX displayed the same cytotoxicity with or without filtration (Fig. 5(C)), demonstrating that free drug molecules can pass freely through the column.

The possibility existed that DOX is released immediately upon contact between the Lipodisqs and the cellular surface. To test this, HeLa cells were pre-incubated with LQ-10\% both for $30 \mathrm{~min}$ on ice and for increasing time at $37^{\circ} \mathrm{C}$, before washing away unbound NPs, after which the incubation continued (Fig. 5(D)). When cell proliferation was assessed $6 \mathrm{~h}$ after initial NP addition, the data showed that potent release of DOX required at least 2-4 h of incubation at $37{ }^{\circ} \mathrm{C}$ (Fig. 5(D)), suggesting that DOX release requires cellular internalization.

After $4 \mathrm{~h}$ of incubation with LQ-10\%, a punctate, cytoplasmic signal from the Lipodisq-conjugated Cy5 was evident in HeLa cells (Fig. 5(E)), consistent with uptake of NPs into cells. The red fluorescence of DOX partially overlapped with the punctate $\mathrm{Cy} 5$ staining, but was also detectable in the nucleus, as expected from free DOX molecules, and consistent with the cytotoxicity observed 

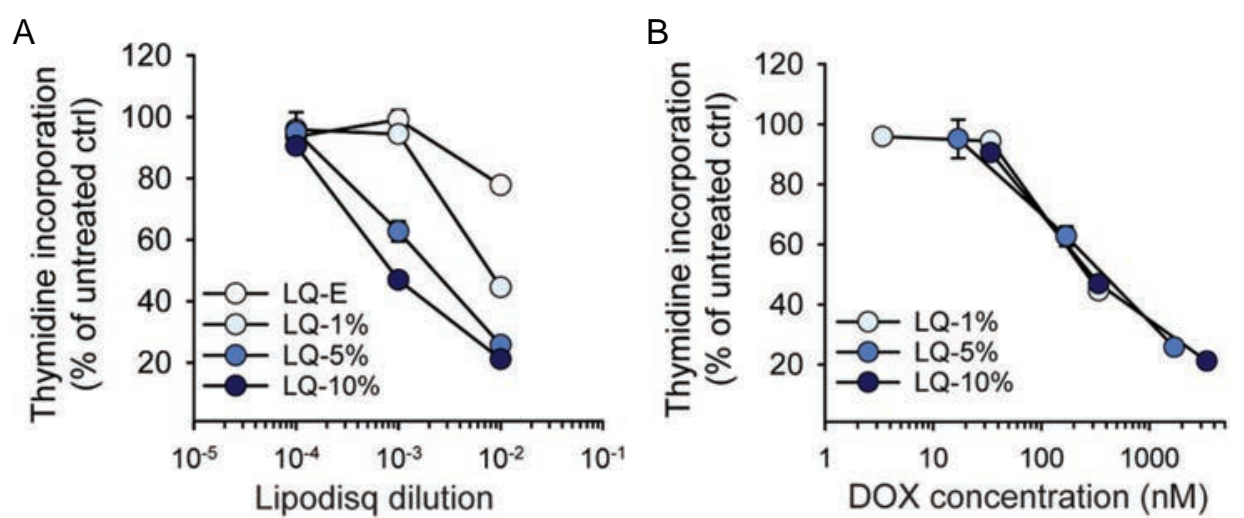

Figure 4. Cytotoxicity of Lipodisqs correlates with DOX loading. HeLa cells were treated with increasing dilutions of empty Lipodisqs (LQ-E) or Lipodisqs loaded with 1\% (LQ-1\%), 5\% (LQ-5\%), or 10\% DOX (LQ-10\%) for $16 \mathrm{~h}$ before thymidine incorporation was assessed, normalized to untreated control, and plotted as a function of Lipodisq dilution (A) or DOX loading (B).

after $4 \mathrm{~h}$ of incubation with Lipodisqs. The punctate Cy5positive structures resembled lysosomes, and indeed, a substantial overlap between the Cy5 signal from LQ-10\% and lysosomes stained by either CellLight LysosomesRFP or the lysosomal dye Lysotracker Green (Figs. 5(F, G)) was observed. Together, these data suggest that Lipodisqs are transported to lysosomes for degradation and that DOX is released from within the endolysosomal system.

\section{DOX is Released from Lipodisq NPs at Low pH}

The internal environment of lysosomes has a $\mathrm{pH}$ of 4.55.0, maintained by lysosomal vATPases [30]. To assess whether a low $\mathrm{pH}$ is required for DOX release, we incubated LQ-10\% for $4 \mathrm{~h}$ in PBS pH 7.4 or 5.0 and compared the cytotoxic effect of the filtrate as a measure of DOX release. As shown in Figure 6(A), incubation at $\mathrm{pH} 5.0$ renders the filtrate significantly more cytotoxic than incubation at $\mathrm{pH} 7.4$, suggesting that the release of DOX is increased at $\mathrm{pH}$ 5.0. Of note, treatment of free DOX at different $\mathrm{pH}$ values does not alter the cytotoxicity of the drug itself (Fig. 6(A)). The release of DOX at low pH was not a spontaneous process, since at least $4 \mathrm{~h}$ of incubation of the LQ-10\% at $\mathrm{pH} 5.0$ was required to provide the filtrate with cytotoxic properties (Fig. 6(B)). The release of DOX at pH 5.0 fits well with earlier data showing that the SMA polymer becomes protonated at this $\mathrm{pH}[10]$ and then dissociates from the lipid. We therefore propose that release of drug from the discoidal NPs occurs as a result of a change in the lipid morphology (and breakdown of the disc structure) at low $\mathrm{pH}$ [10]. We cannot exclude the possibility that also lipases that are active at low $\mathrm{pH}$ contribute to disc breakdown and DOX release.

To assess whether the degree of endosomal and lysosomal acidification affects the cytotoxicity of Lipodisq NPs, HeLa cells were treated with well-known inhibitors of lysosomal vATPases, Bafilomycin A1 (BafA1) and Concanamycin A (ConA) [31]. To verify that acidification was abolished by the inhibitors, HeLa cells were stained with the acid-sensitive Lysotracker Green dye, which is trapped selectively within acidic compartments when protonated. In the presence of the two inhibitors, the punctate staining previously observed in control cells was completely abolished (Fig. 6(C)) and the cytotoxicity of LQ-10\% was significantly reduced (Fig. 6(D)), consistent with a reduced release of DOX from the NPs.

\section{DOX-Loaded Lipodisqs Exert Cytotoxic Action Across a Panel of Cancer Cell Lines}

To test whether the data obtained in HeLa cells are representative for other in vitro systems, the cytotoxicity of empty Lipodisqs (LQ-E) with that of DOX-loaded Lipodisqs (LQ-10\%) and free DOX was compared across a panel of cell lines from breast and colorectal cancer origin; MCF7, MDA-MB-468, SKBR3, and MDAMB-231, or HCT116 and SW480, respectively. Although the cytotoxic effect differed between these cell lines, the toxicity of the DOX-loaded Lipodisqs was similar to that obtained with free DOX and much higher than that obtained with the empty Lipodisqs (Fig. 7). Comparable data were obtained after $72 \mathrm{~h}$ of incubation (our unpublished observations). Moreover, LQ-10\% exerted different cellular effects depending on the concentrations added. At relatively low concentrations (approx. $340 \mathrm{nM}$ DOX content) typical signs of senescence were observed; the cells were reduced in number, flattened and enlarged (our unpublished observations). DOX is a well-known inducer of senescence and in accordance with this, the same phenotypes were observed at low DOX concentrations. In contrast, high concentrations of both LQ-10\% and free DOX led to cell death.

\section{Biodistribution of Lipodisqs in Mice Showed a High Liver Uptake and Rapid Biliary Excretion}

To study the biodistribution of Lipodisq NPs, the Cy5 fluorophore was covalently conjugated to either the SMA polymer or to the lipid DLPE (see Table I). Whole body images 
A

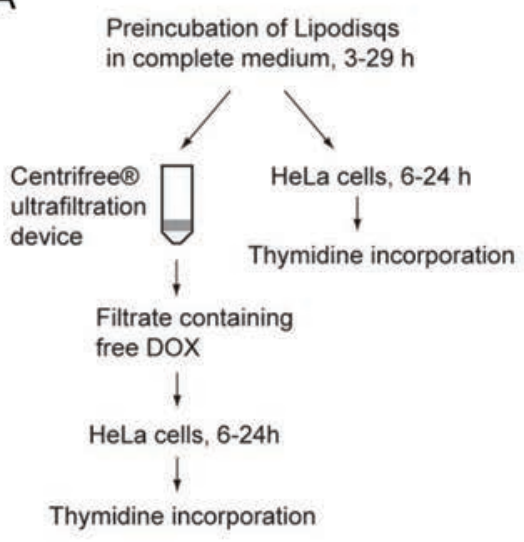

B

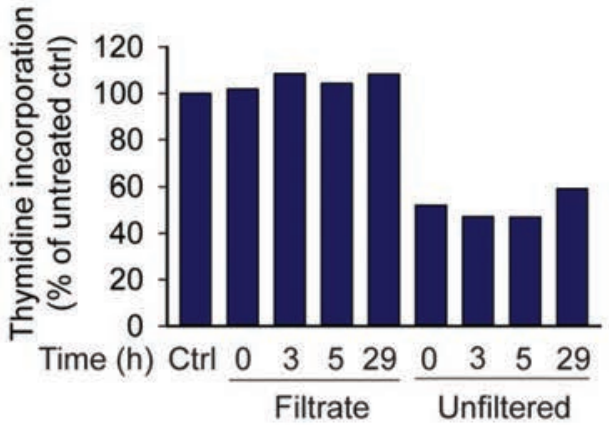

C

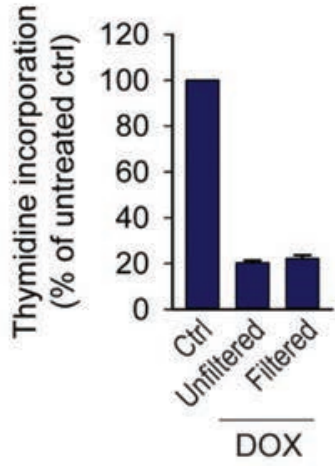

D
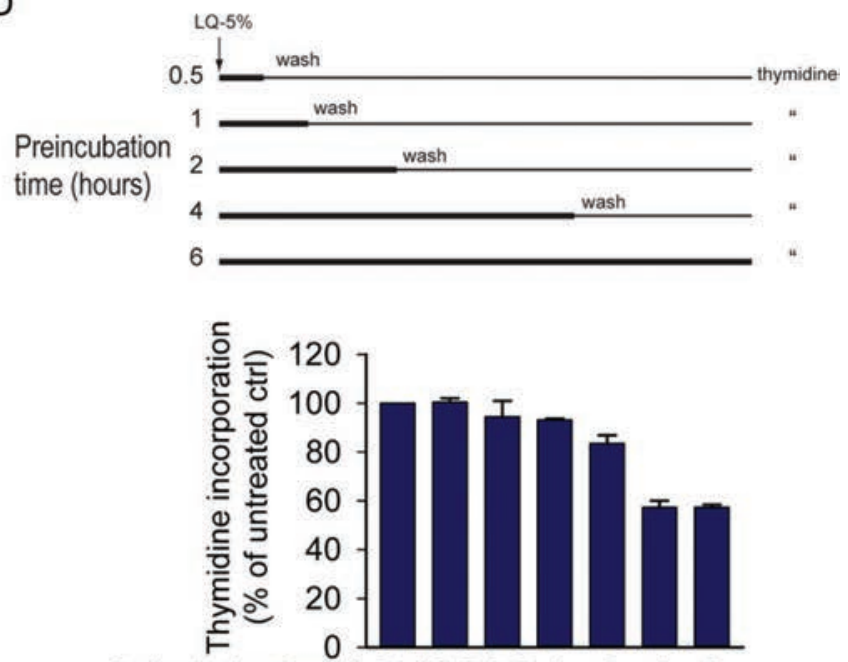

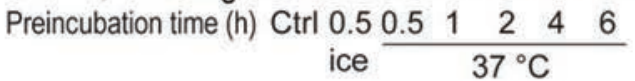
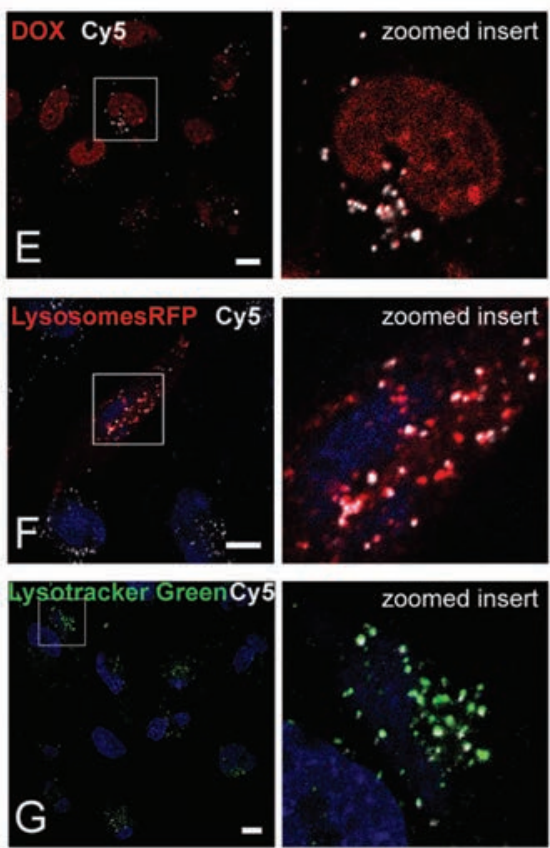

Figure 5. The release of DOX from Lipodisqs requires cellular uptake. (A) Workflow for the use of Centrifree ${ }^{\circledR}$ Ultrafiltration device for crude determination of DOX release from Lipodisqs. (B) LQ-5\% (1:100) was incubated at $37{ }^{\circ} \mathrm{C}$ for 3,5 or $29 \mathrm{~h}$ in complete growth medium in the absence of cells. Then the filtrate or unfiltered Lipodisqs were added to HeLa cells and incubated for $16 \mathrm{~h}$ before thymidine incorporation was assessed. (C) HeLa cells treated with unfiltered or filtered free DOX (340 nM) for $24 \mathrm{~h}$. (D) Four hours of Lipodisq uptake is sufficient for maximal cytotoxic effect. HeLa cells were treated with Lipodisqs (LQ-10\% 1:100) for $30 \mathrm{~min}$ on ice or for $0.5-6 \mathrm{~h}$ at $37^{\circ} \mathrm{C}$, before unbound Lipodisqs were removed by washing. Thereafter the incubation was continued, and $6 \mathrm{~h}$ after Lipodisq addition, thymidine incorporation was assessed; mean values from duplicates. (E-G) Lipodisqs are rapidly internalized to lysosomes in HeLa cells. HeLa cells were treated with Cy5-labeled Lipodisqs containing 10\% DOX (LQ$10 \%, 1: 100)$ for $4 \mathrm{~h}(\mathrm{E})$. For staining of lysosomes, HeLa cells were either transduced with BacMam CellLight ${ }^{\mathrm{TM}}$ LysosomesRFP and incubated for $16 \mathrm{~h}(\mathrm{~F})$, or stained with Lysotracker Green $(100 \mathrm{nM}) 5 \mathrm{~min}$ before imaging $(\mathrm{G})$. The cells were incubated with empty Cy5-labeled Lipodisqs (LQ-E, 1:10) for $4 \mathrm{~h}$ and the nuclei stained by Hoechst (1.6 $\mu \mathrm{M}$ ); scale bar $10 \mu \mathrm{m}$.

were obtained using the IVIS ${ }^{\circledR}$ Spectrum scanner (Fig. 8), and mice were sacrificed at the given time points such that organs could be harvested and visualised ex vivo (data not shown and Fig. 9). The majority of fluorescence from both
Lipodisq preparations was recovered in liver, which is consistent with previous observations for other i.v. injected NPs [32]. However, contrary to that reported for most NPs, only a small fraction of Lipodisq NPs was recovered in 
A
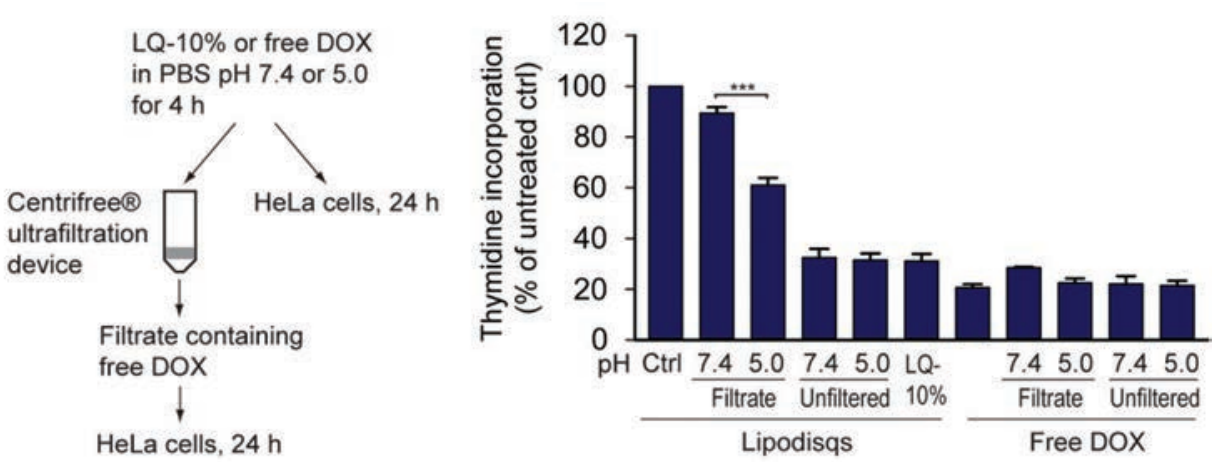

B

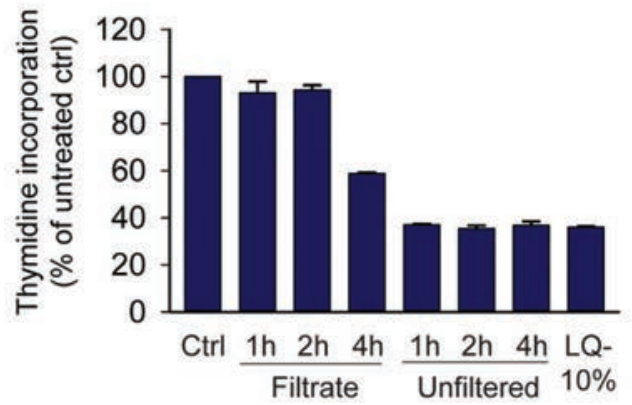

C

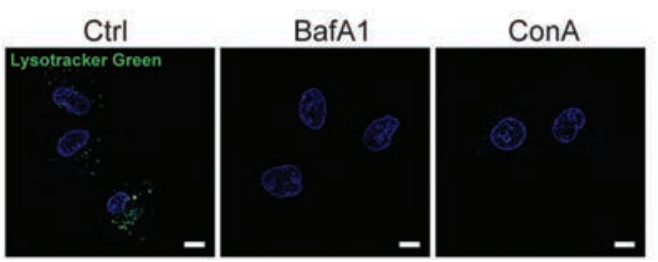

D

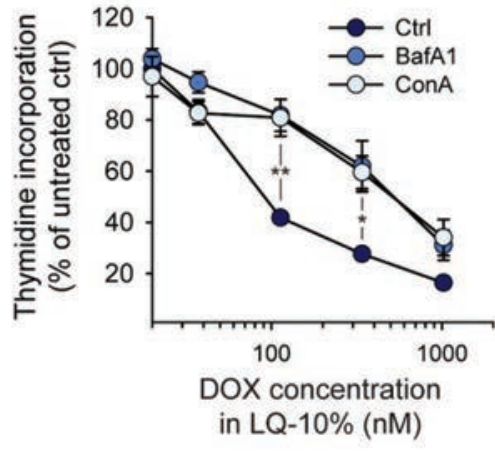

Figure 6. Low pH environment leads to release of DOX from Lipodisqs. (A) LQ-10\% (1:25) or free DOX (13.6 $\mu \mathrm{M})$ was incubated in PBS pH 7.4 or 5.0 at $37{ }^{\circ} \mathrm{C}$ for $4 \mathrm{~h}$. After passing half of the sample through Centrifree columns, the filtrate and unfiltered sample was added to HeLa cells and thymidine incorporation determined $24 \mathrm{~h}$ later; mean values \pm SEM from three independent experiments; free DOX: two independent experiments with deviation from the mean; ${ }^{* * *}, p<0.001$; two-sided student's $t$-test. (B) The release of DOX at low pH is not a spontaneous process, but rather takes time. LQ-10\% (1:25) was incubated in PBS pH 5.0 at $37^{\circ} \mathrm{C}$ for 1,2 or $4 \mathrm{~h}$. The filtrates or unfiltered samples were added to HeLa cells and thymidine incorporation determined $24 \mathrm{~h}$ later; mean values from one experiment with duplicates. (C) HeLa cells pre-treated for $1 \mathrm{~h}$ with Bafilomycin A1 (BafA1, 25 $\mathrm{nM}$ ) or Concanamycin A (ConA, $25 \mathrm{nM}$ ) were stained by Lysotracker Green (100 nM) and the nuclear stain Hoechst (1.6 $\mu \mathrm{M})$ for $5 \mathrm{~min}$ before image aquisition; scale bar $10 \mu \mathrm{m}$. (D) HeLa cells were treated with increasing concentrations of LQ-10\% for $24 \mathrm{~h}$ in the absence or presence of BafA1 (50 nM) or ConA (40 nM). Then thymidine incorporation was assessed, and the data were normalized to non Lipodisq-treated cells for each series; mean values \pm SEM from three independent experiments; ${ }^{*}, p<0.05 ;{ }^{* *}$, $p<0.01$; two-sided student's $t$-test.

spleen. Notably, there seemed to be a higher fluorescence in animals receiving SMA-Cy5 than DLPE-Cy5. It is not likely that this difference is caused merely by a higher fluorescence of the SMA-Cy5 preparation, since the fluorescence of SMA-Cy5 was found to be only $11 \%$ higher than that of DLPE-Cy5 before injection (data not shown). We favour the idea that some DLPE-Cy5 may be released (see below). Furthermore, surprisingly high levels of fluorescence following injections of both these substances were observed in colon already $1 \mathrm{~h}$ after injection (our unpublished observations), indicating a rapid biliary excretion. To study the colon accumulation in more detail, the colon was imaged in the subsequent study also after removal of feces, and both feces and empty colon was imaged
(Fig. 9). The images and the quantitative data obtained clearly demonstrate that the fluorophore is rapidly excreted into feces (Fig. 9). Thus, our biodistribution data show a high recovery of Lipodisqs in liver, followed by a rapid biliary excretion into feces of some of the NPs or Cy5containing substances. We suggest that the liver uptake is due to the ability of these very small NPs $(10 \mathrm{~nm}$ in diameter, $4.5 \mathrm{~nm}$ thickness) to pass the fenaestra of the liver sinusoidal endothelial cells [33], before being endocytosed by hepatocytes [34] and then excreted into bile [35].

By comparing the data obtained 4 and $24 \mathrm{~h}$ after injection (Figs. 8 and 9), it is clear that DLPE-Cy5 is excreted faster than SMA-Cy5. This difference may be due to metabolic release of some of the DLPE-Cy5 lipid from 

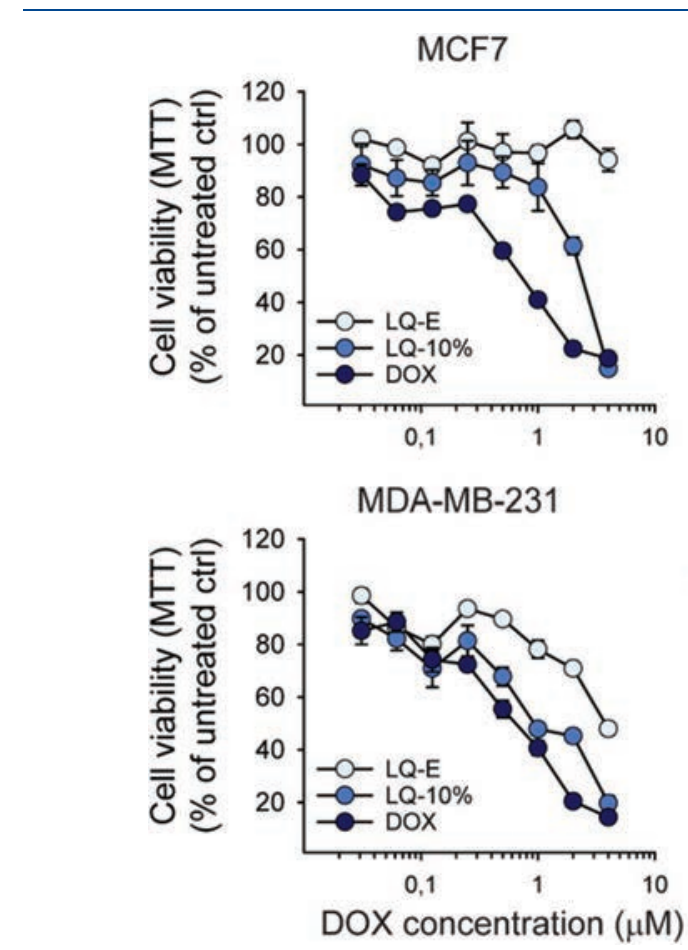

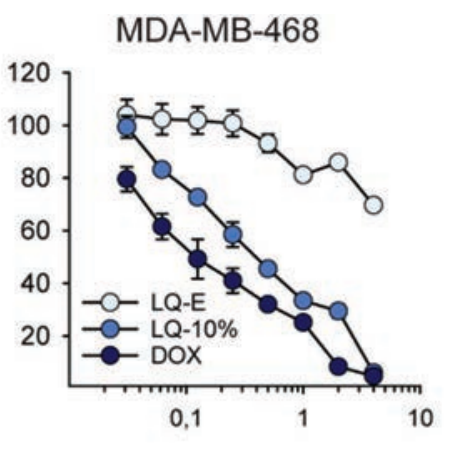

HCT116

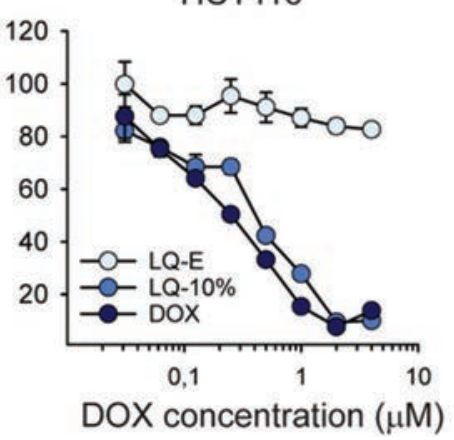

SKBR3

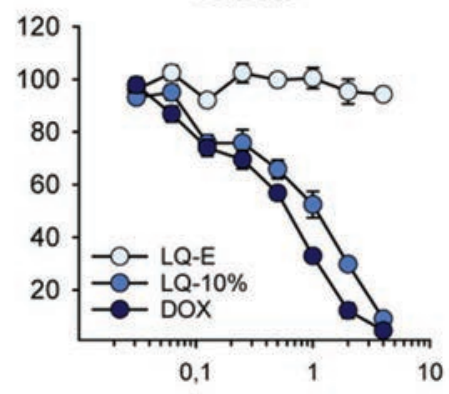

SW480

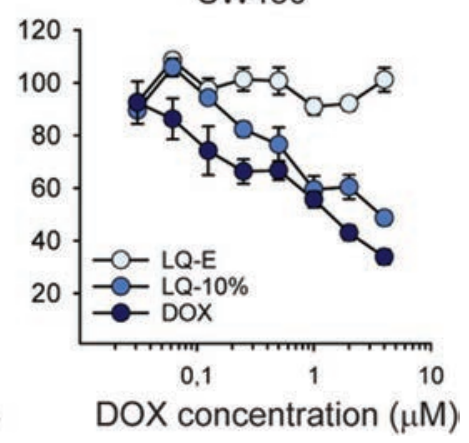

Figure 7. Cytotoxicity of Lipodisqs versus free DOX across a panel of cancer cell lines. The indicated cell lines were treated for $48 \mathrm{~h}$ with increasing concentrations of free DOX or with equivalent concentrations of DOX-loaded Lipodisqs (LQ-10\%) and the same dilutions of empty Lipodisqs (LQ-E). Cell viability was assessed by the MTT assay. All values were normalized to that of untreated control cells, and the error bars represent standard deviation between triplicates from one representative experiment. The values of the errors are sometimes too low to be detected behind the large circles.

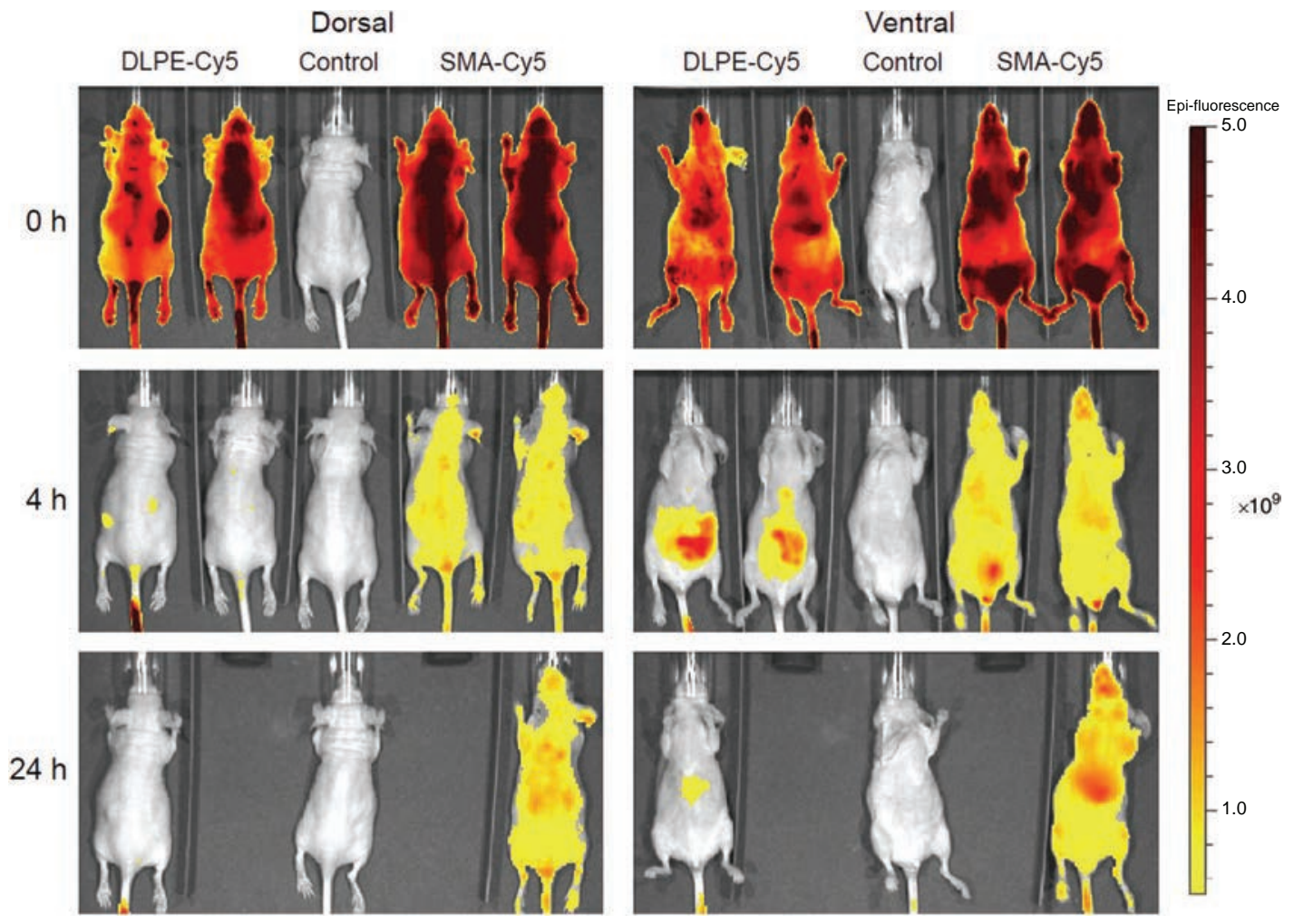

Figure 8. Whole body fluorescence images. Images with dorsal and ventral views were obtained immediately after injection $(0 \mathrm{~h})$ as well as 4 and $24 \mathrm{~h}$ after injection of DLPE-Cy5, SMA-Cy5 or saline as control. The images are not corrected for an $11 \%$ higher fluorescence of SMA-Cy5 compared to DLPE-Cy5. 


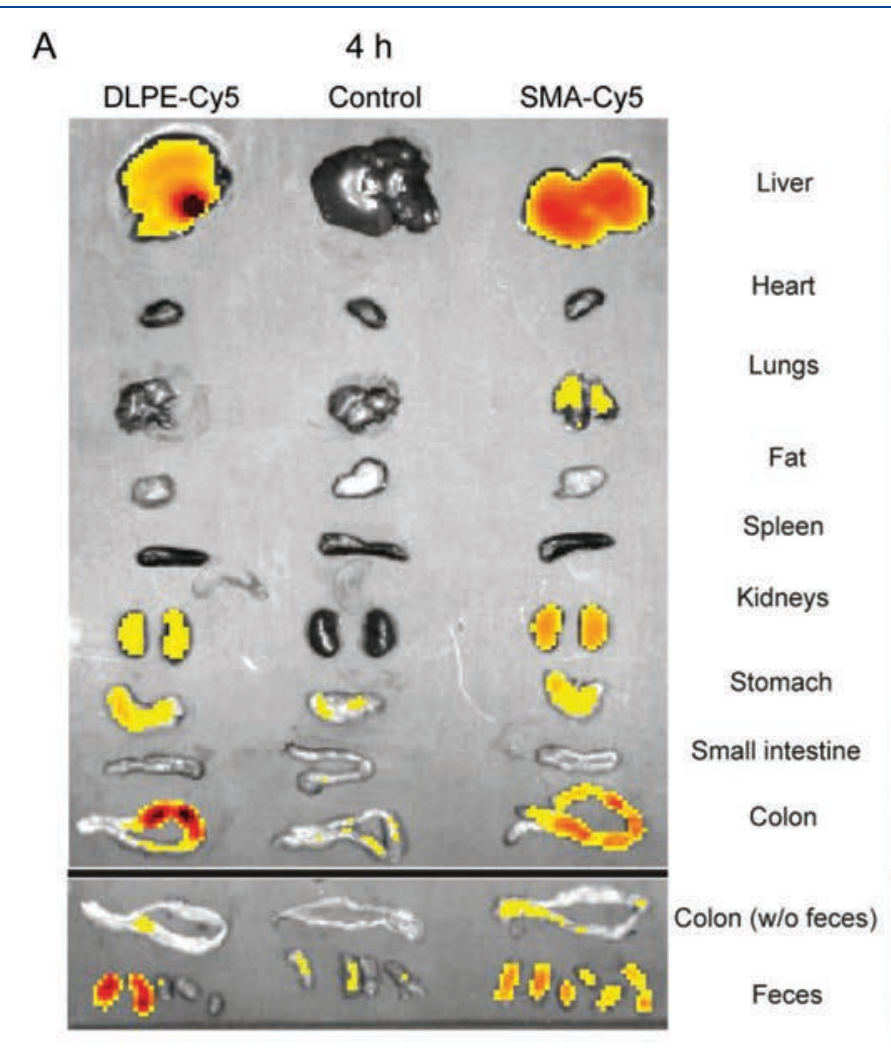

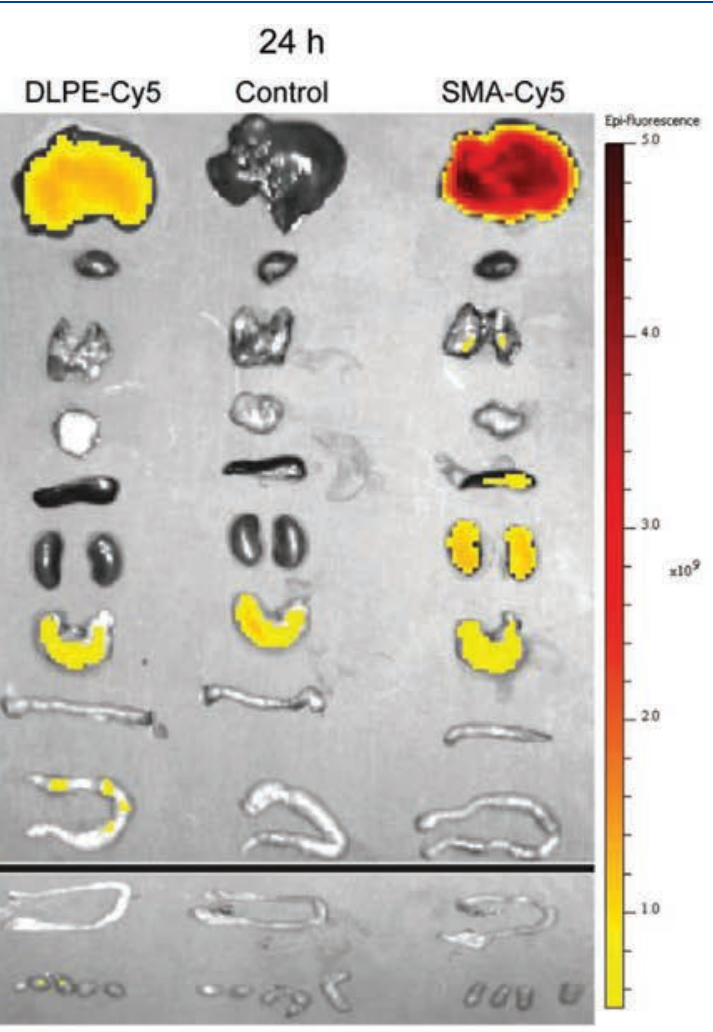

B

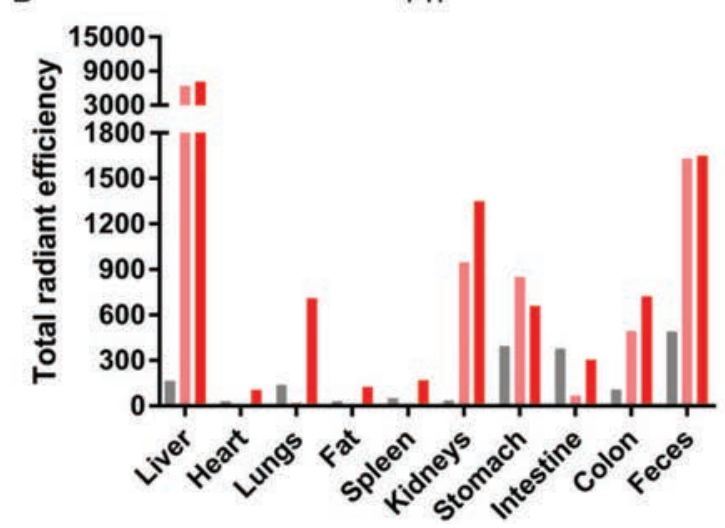

$24 \mathrm{~h}$

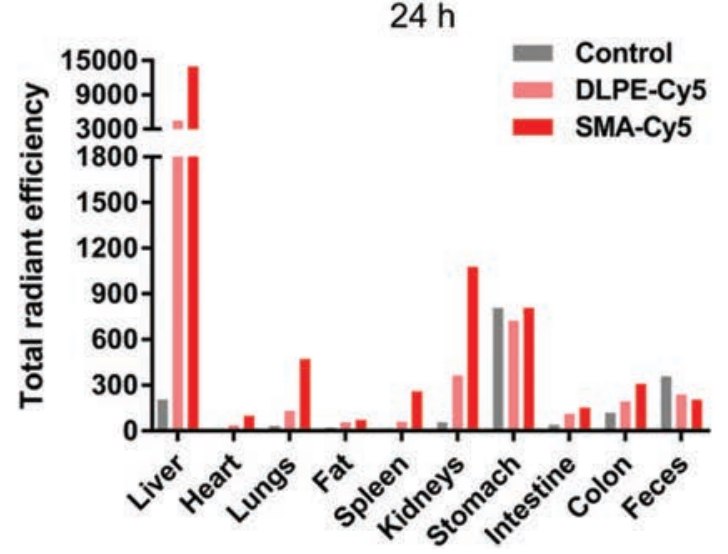

Figure 9. Ex vivo fluorescence images of isolated organs after injection of Cy5-labelled Lipodisqs. (A) Organs obtained 4 and $24 \mathrm{~h}$ after injection of SMA-Cy5, DLPE-Cy5 and saline as a control. Colon was imaged both as harvested and after removal of feces. (B) Quantification of fluorescence obtained from the tissues in (A). The data are not corrected for a $11 \%$ higher fluorescence of SMA-Cy5 compared to DLPE-Cy5.

these NPs. In contrast to the other tissues, the fluorescence from SMA-Cy5 strongly increased in liver from 4 to $24 \mathrm{~h}$ after injection.

The biodistribution data showing high liver uptake and rapid biliary excretion of Lipodisqs following i.v. injection in mice (Fig. 9), differ slightly from biodistribution data recently reported for similar NPs [36]. Tanaka et al. made SMA-containing partices $(8-10 \mathrm{~nm})$ using the phospholipid PC16:0/18:1, and measured biodistribution following i.v. injection detected by ${ }^{111}$ In-DTPA bound to PE18:0/18:0. They reported that per $g$ tissue, the spleen contained $31 \%$ and $25 \%$ of that in liver at 3 and $24 \mathrm{~h}$ after injection, respectively. For comparison, the numbers obtained in our study 4 and $24 \mathrm{~h}$ after injection was $1.4 \%$ and $7.1 \%$, respectively, for the DLPE-Cy5 labelled NPs and $12.6 \%$ and $13.6 \%$ for the SMA-Cy5 labelled NPs. Furthermore, Tanaka et al. [36] reported that the amount of radioactivity in kidneys (per $g$ tissue) was approx. $10 \%$ of that in liver at both time points, whereas much higher values were obtained for the Lipodisq NPs, (39\% and 28\% for the DLPE-Cy5 labelled NPs at 4 and $24 \mathrm{~h}$ after injection and $62 \%$ and $18 \%$ for the SMA-Cy5 labelled NPs). 
The much higher relative content in kidney than liver for the Lipodisqs are most likely explained by the rapid removal from liver by biliary excretion of these NPs. Tanaka et al. did not discuss biliary excretion or the potential presence of their NPs in feces.

Huda et al. [37] have also performed biodistribution studies of discoidal NPs formed by using PC16:0/18:1 and MSP1E3D1 protein in place of SMA. NPs of $13 \mathrm{~nm}$ were obtained and the biodistribution was evaluated by PET/CT following injection of particles labelled with ${ }^{64} \mathrm{Cu}$-DOTA to lysine groups in the protein. These NPs were reported to permeate deeply into cancer tissue, to show a high accumulation in kidney and a rapid renal excretion [37]. A rapid renal excretion of NPs of $13 \mathrm{~nm}$ is unexpected [38]. As these ${ }^{64} \mathrm{Cu}$-labelled NPs released considerable amounts of radioactivity following in vitro incubation with mouse plasma at $37^{\circ} \mathrm{C}$ for $12 \mathrm{~h} \mathrm{[37],} \mathrm{it}$ is tempting to speculate the at least part of the radioactivity recovered in kidneys was due to release of the radiochemical labelling of the NPs, rather than the excretion of intact NPs.

The biodistribution pattern of Lipodisq NPs reported here, suggests that they are promising candidates for hydrophobic drug delivery to liver. Moreover, the rapid excretion into bile is interesting regarding the possibility to use these NPs for in vivo imaging. For a contrast agent to be useful for medical imaging, it is very important that the agent is rapidly excreted to produce a good contrast between the diseased area and the surrounding tissue. In most cases, rapid excretion is essential to obtain a low signal in the surrounding tissue [39]. Most contrast agents for medical imaging are sufficiently small and hydrophilic to be rapidly excreted into urine. This has, however, the drawback that it may be difficult to image diseased areas close to the kidneys or the urinary tract. NPs that are rapidly excreted into bile may therefore be a suitable platform for new contrast agents. In addition, the rapid biliary excretion of Lipodisqs, and also their similarities to HDL [6], suggests that these NPs may be suitable for delivery of drugs and contrast agents to atherosclerotic tissue [40]. Moreover, it may be possible to change or optimalize the pharmacokinetics of these NPs, by coupling PEG to the Lipodisqs (either to the lipids or the SMA polymer) as recently demonstrated for synthetic HDL NPs [41]. In summary, Lipodisqs should be explored further as candidates for the delivery of drugs and contrast agents.

Acknowledgments: The work in Oslo was supported by the Research Council of Norway (NANO2021; NANOCAN project no. 228200 and nanoAUTOPHAGY project no. 274574), The Norwegian Cancer Society and Helse Sør-Øst, Norway. We thank the Department for Comparative Medicine for the services they provided. The work in Oxford was supported by the UK EPSRC (research grant number EP/I029516/1),
EURAMET (BiOrigin research grant HLT10) and the National Physical Laboratory.

\section{REFERENCES}

1. Desai, P.P., Date, A.A. and Patravale, V.B., 2012. Overcoming poor oral bioavailability using nanoparticle formulationsopportunities and limitations. Drug Discovery Today: Technologies, 9(2), pp.e87-e95.

2. Torchilin, V.P., 2014. Multifunctional, stimuli-sensitive nanoparticulate systems for drug delivery. Nature Reviews Drug Discovery, 13(11), pp.813-827.

3. Shi, J., Kantoff, P.W., Wooster, R. and Farokhzad, O.C., 2017. Cancer nanomedicine: Progress, challenges and opportunities. Nature Reviews Cancer, 17(1), pp.20-37.

4. Matsumura, Y. and Maeda, H., 1986. A new concept for macromolecular therapeutics in cancer chemotherapy: Mechanism of tumoritropic accumulation of proteins and the antitumor agent smancs. Cancer Research, 46(12), pp.6387-6392.

5. Puri, A., Loomis, K., Smith, B., Lee, J.H., Yavlovich, A., Heldman, E. and Blumenthal, R., 2009. Lipid-based nanoparticles as pharmaceutical drug carriers: from concepts to clinic. Critical Reviews in Therapeutic Drug Carrier Systems, 26(6), pp.523-580.

6. Murakami, T., 2012. Phospholipid nanodisc engineering for drug delivery systems. Biotechnology Journal, 7(6), pp.762-767.

7. Gabizon, A., Chemla, M., Tzemach, D., Horowitz, A.T. and Goren, D., 1996. Liposome longevity and stability in circulation: Effects on the in vivo delivery to tumors and therapeutic efficacy of encapsulated anthracyclines. Journal of Drug Targeting, 3(5), pp.391-398.

8. Barenholz, Y., 2012. Doxil(R)—The first FDA-approved nano-drug: Lessons learned. Journal of Controlled Release, 160(2), pp.117-134.

9. Allen, T.M. and Cullis, P.R., 2013. Liposomal drug delivery systems: From concept to clinical applications. Advanced Drug Delivery Reviews, 65(1), pp.36-48.

10. Bada Juarez, J.F., Harper, A.J., Judge, P.J., Tonge, S.R. and Watts, A., 2019. From polymer chemistry to structural biology: The development of SMA and related amphipathic polymers for membrane protein extraction and solubilisation. Chemistry and Physics of Lipids, 221, pp.167-175.

11. Orwick, M.C., Judge, P.J., Procek, J., Lindholm, L., Graziadei, A., Engel, A., Grobner, G. and Watts, A., 2012. Detergent-free formation and physicochemical characterization of nanosized lipidpolymer complexes: Lipodisq. Angewandte Chemie International Edition, 51(19), pp.4653-4657.

12. Jamshad, M., Grimard, V., Idini, I., Knowles, T.J., Dowle, M.R., Schofield, N., Sridhar, P., Lin, Y., Finka, R., Wheatley, M., Thomas, O.R.T., Palmer, R.E., Overduin, M., Govaerts, C., Ruysschaert, J.-M., Edler, K.J. and Dafforn, T.R., 2015. Structural analysis of a nanoparticle containing a lipid bilayer used for detergent-free extraction of membrane proteins. Nano Research, 8(3), pp.774-789.

13. Arouri, A., Hansen, A.H., Rasmussen, T.E. and Mouritsen, O.G., 2013. Lipases, liposomes and lipid-prodrugs. Current Opinion in Colloid \& Interface Science, 18(5), pp.419-431.

14. Mashaghi, S., Jadidi, T., Koenderink, G. and Mashaghi, A., 2013. Lipid nanotechnology. International Journal of Molecular Sciences, 14(2), pp.4242-4282.

15. Thorn, C.F., Oshiro, C., Marsh, S., Hernandez-Boussard, T., McLeod, H., Klein, T.E. and Altman, R.B., 2011. Doxorubicin pathways: Pharmacodynamics and adverse effects. Pharmacogenetics and Genomics, 21(7), pp.440-446.

16. Tacar, O., Sriamornsak, P. and Dass, C.R., 2013. Doxorubicin: An update on anticancer molecular action, toxicity and novel drug delivery systems. Journal of Pharmacy and Pharmacology, 65(2), pp.157-170. 
17. Pugazhendhi, A., Edison, T., Velmurugan, B.K., Jacob, J.A. and Karuppusamy, I., 2018. Toxicity of Doxorubicin (Dox) to different experimental organ systems. Life Sciences, 200, pp.26-30.

18. Knowles, T.J., Finka, R., Smith, C., Lin, Y.P., Dafforn, T. and Overduin, M., 2009. Membrane proteins solubilized intact in lipid containing nanoparticles bounded by styrene maleic acid copolymer. Journal of the American Chemical Society, 131(22), pp.7484-7485.

19. Lindhoud, S., Carvalho, V., Pronk, J.W. and Aubin-Tam, M.E., 2016. SMA-SH: Modified styrene-maleic acid copolymer for functionalization of lipid nanodiscs. Biomacromolecules, 17(4), pp.1516-1522.

20. Huang, A., Huang, L. and Kennel, S.J., 1980. Monoclonal antibody covalently coupled with fatty acid. A reagent for in vitro liposome targeting. Journal of Biological Chemistry, 255(17), pp.80158018.

21. Karczmar, G.S. and Tritton, T.R., 1979. The interaction of adriamycin with small unilamellar vesicle liposomes. A fluorescence study. Biochimica et Biophysica Acta, 557(2), pp.306-319.

22. de Wolf, F.A., Maliepaard, M., van Dorsten, F., Berghuis, I., Nicolay, K. and de Kruijff, B., 1990. Comparable interaction of doxorubicin with various acidic phospholipids results in changes of lipid order and dynamics. Biochimica et Biophysica Acta, 1096(1), pp.67-80.

23. Alves, A.C., Magarkar, A., Horta, M., Lima, J., Bunker, A., Nunes, C. and Reis, S., 2017. Influence of doxorubicin on model cell membrane properties: insights from in vitro and in silico studies. Scientific Reports, 7(1), p.6343.

24. Dupou-Cezanne, L., Sautereau, A.M. and Tocanne, J.F., 1989. Localization of adriamycin in model and natural membranes. Influence of lipid molecular packing. European Journal of Biochemistry, 181(3), pp.695-702.

25. Gallois, L., Fiallo, M. and Garnier-Suillerot, A., 1998. Comparison of the interaction of doxorubicin, daunorubicin, idarubicin and idarubicinol with large unilamellar vesicles. Circular dichroism study. Biochimica et Biophysica Acta, 1370(1), pp.31-40.

26. Anand, R., Malanga, M., Manet, I., Manoli, F., Tuza, K., Aykac, A., Ladaviere, C., Fenyvesi, E., Vargas-Berenguel, A., Gref, R. and Monti, S., 2013. Citric acid-gamma-cyclodextrin crosslinked oligomers as carriers for doxorubicin delivery. Photochemical and Photobiological Sciences, 12(10), pp.1841-1854.

27. Karukstis, K.K., Thompson, E.H., Whiles, J.A. and Rosenfeld, R.J., 1998. Deciphering the fluorescence signature of daunomycin and doxorubicin. Biophysical chemistry, 73(3), pp.249-263.

28. Wohlfarth, C., 2008. Static Dielectric Constants of Pure Liquids and Binary Liquid Mixtures. Berlin, Germany, Springer verlag.
29. Mindell, J.A., 2012. Lysosomal acidification mechanisms. Annual Review of Physiology, 74, pp.69-86.

30. Huss, M. and Wieczorek, H., 2009. Inhibitors of V-ATPases: Old and new players. The Journal of Experimental Biology, 212(3), pp.341-346.

31. Skotland, T., Iversen, T.G. and Sandvig, K., 2010. New metal-based nanoparticles for intravenous use: Requirements for clinical success with focus on medical imaging. Nanomedicine, 6, pp.730-737.

32. Sorensen, K.K., Simon-Santamaria, J., McCuskey, R.S. and Smedsrod, B., 2015. Liver sinusoidal endothelial cells. Comprehensive Physiology, 5(4), pp.1751-1774.

33. Schroeder, B. and McNiven, M.A., 2014. Importance of endocytic pathways in liver function and disease. Comprehensive Physiology, 4(4), pp.1403-1417.

34. Boyer, J.L., 2013. Bile formation and secretion. Comprehensive Physiology, 3(3), pp.1035-1078.

35. Tanaka, M., Hosotani, A. and Mukai, T., 2018. Indium-111 labeling of high-density lipoprotein-mimicking phospholipid-styrene maleic acid copolymer complexes and its biodistribution in mice. Journal of Labelled Compounds and Radiopharmaceuticals, 61(11), pp.857-863.

36. Huda, P., Binderup, T., Pedersen, M.C., Midtgaard, S.R., Elema, D.R., Kjaer, A., Jensen, M. and Arleth, L., 2015. PET/CT based in vivo evaluation of ${ }^{64} \mathrm{Cu}$ labelled nanodiscs in tumor bearing mice. PLoS One, 10(7), p.e0129310.

37. Choi, H.S., Liu, W., Misra, P., Tanaka, E., Zimmer, J.P., Itty, I.B., Bawendi, M.G. and Frangioni, J.V., 2007. Renal clearance of quantum dots. Nature Biotechnology, 25(10), pp.1165-1170.

38. Skotland, T., 2012. Molecular imaging: Challenges of bringing imaging of intracellular targets into common clinical use. Contrast Media \& Molecular Imaging, 7(1), pp.1-6.

39. Perez-Medina, C., Binderup, T., Lobatto, M.E., Tang, J., Calcagno, C., Giesen, L., Wessel, C.H., Witjes, J., Ishino, S., Baxter, S., Zhao, Y., Ramachandran, S., Eldib, M., Sanchez-Gaytan, B.L., Robson, P.M., Bini, J., Granada, J.F., Fish, K.M., Stroes, E.S., Duivenvoorden, R., Tsimikas, S., Lewis, J.S., Reiner, T., Fuster, V., Kjaer, A., Fisher, E.A., Fayad, Z.A. and Mulder, W.J., 2016. In vivo PET imaging of HDL in multiple atherosclerosis models. JACC: Cardiovascular Imaging, 9(8), pp.950-961.

40. Li, D., Fawaz, M.V., Morin, E.E., Ming, R., Sviridov, D., Tang, J., Ackermann, R., Olsen, K., Remaley, A.T. and Schwendeman, A., 2018. Effect of synthetic high density lipoproteins modification with polyethylene glycol on pharmacokinetics and pharmacodynamics. Molecular Pharmaceutics, 15(1), pp.83-96. 